\title{
Educação popular e ensino superior em Paulo Freire
}

\author{
Celso de Rui Beisiege ${ }^{2}$
}

\section{Resumo}

0 artigo retoma e desenvolve reflexões a propósito de questões examinadas durante seminário internacional sobre a Educação Superior em Paulo Freire. Propõe o estudo do tema no âmbito de uma reflexão mais abrangente sobre as articulações da educação popular e do ensino das elites durante o longo período recoberto pela práxis do educador no Brasil e no exterior.

\section{Palavras-chave}

Educação popular - Educação das elites - Expansão da escolaridade - Paulo Freire e educação superior - Celso Beisiegel.

\section{Popular education and higher education in Paulo Freire}

\section{Abstract}

The article revisits and develops reflections about the issues examined during the international seminar on Paulo Freire on Higher Education. It proposes to study the theme by expanding the scope to include the articulation of popular education and the education of the elites during the extensive period covered by the educator's praxis in Brazil and abroad.

\section{Keywords}

Popular education - Education of the elites - Schooling expansion - Paulo Freire and higher education - Celso Beisiegel.

1- Publicação póstuma de artigo inédito do autor.

2- Foi professor da Faculdade de Educação da Universidade de São Paulo. São Paulo, SP. Brasil. 


\title{
O ARTIGo
}

\section{Educação popular e ensino superior em Paulo Freire}

\author{
Celso de Rui Beisiegel
}

Em novembro de 2013, apresentei num seminário internacional dedicado ao estudo de questões suscitadas pelo tema da educação superior em Paulo Freire ${ }^{3}$, uma comunicação intitulada "A educação superior em Paulo Freire: uma proposta de orientação para a pesquisa”. 0 tempo disponível para a exposição, cerca de 30 minutos, era insuficiente para uma exploração mais circunstanciada das posições de Freire nas questões referentes à educação superior. Entre outros objetivos, este artigo tem a intenção de aprofundar o exame de problemas então levantados.

As discussões sobre o tema envolviam dificuldades. A primeira delas estava na escassez de publicações ou outras manifestações de Paulo Freire sobre questões específicas do ensino superior. Mais ainda, como minhas pesquisas orientavam-se sob a perspectiva da atuação do educador junto às classes subalternas, especialmente na conscientização e alfabetização de jovens e adultos analfabetos ou pouco escolarizados, suas eventuais análises sobre aspectos específicos do ensino superior, ou análises potencialmente sugestivas para os estudos sobre esse nível da escolaridade, poderiam até passar despercebidas nas minhas leituras.

A imagem de Freire quase sempre evocou propostas práticas e reflexões teóricas voltadas para a formação das populações subalternas. Esta observação é aceitável para o conjunto de sua obra. Mas era importante ressaltar que seus trabalhos junto às populações desfavorecidas fundamentavam-se em perspectivas teóricas abrangentes sobre o homem, a sociedade e a educação. Por isso mesmo, em suas publicações e atividades, era provável encontrar-se um rico acervo de possíveis contribuições também para a teoria e a prática no ensino superior.

A comunicação apontava duas principais possibilidades de encaminhamento de futuras pesquisas a propósito das posições de Paulo Freire sobre a educação superior. A primeira, mais direta e evidente, envolvia o rastreamento de suas reflexões e intervenções práticas nas questões da educação superior, ao longo de toda sua obra em livros, artigos, escritos em coautoria, palestras, entrevistas, conversas e, especialmente, no magistério no ensino universitário no Recife, em Santiago do Chile, em Harvard, em Genebra, na Unicamp e na PUCSP. Pesquisas dessa natureza recobririam extenso campo de coleta e análise de informações. E tudo indica que ao menos nos escritos mais conhecidos do educador haveria poucas manifestações a propósito desse nível da escolaridade. Uma segunda possibilidade de investigação seria bem mais complexa e estaria sempre sujeita a

3- Seminário promovido pela Uninove em novembro de 2013. 
inevitáveis divergências de interpretação dos pesquisadores. Seria o caso de investigar as possíveis contribuições do educador mediante a utilização do método de trabalho praticado reiteradamente, por ele mesmo, nas análises e reflexões a propósito da educação popular. Isto é, chegar às posições de Paulo Freire sobre o ensino superior considerando-as como decorrências de suas concepções mais gerais sobre o homem, a educação e a sociedade.

Cabe finalmente considerar que a situação do ensino mudou radicalmente desde os meados do século anterior. Na década de 1940, quando Freire apenas iniciava sua prática, os degraus superiores da escolaridade ainda eram pouco acessiveis e não apareciam no universo de expectativas da grande maioria dos habitantes.

0 pensamento e as práticas do educador também mudaram bastante ao longo de sua atividade. Por isso mesmo, a discussão de suas posições sobre a educação, incluindose aí a educação superior, envolve a retomada de algumas questões mais gerais sobre as mudanças da educação escolar no período ora considerado.

\section{A educação popular}

Na bibliografia sobre as instituições escolares no Brasil, a expressão educação popular é empregada com significados diferentes. Convém examinar alguns deles, antes do aprofundamento da discussão sobre seus conteúdos e implicações.

A distinção entre educação popular e educação das elites era bem evidente nos meados do século anterior. Não obstante a igualdade formal de direitos da cidadania republicana, as desigualdades socioeconômicas constitutivas da sociedade capitalista, e tradições culturais geradas no passado semicolonial, ainda marcavam todas as dimensões da vida coletiva. Na educação escolar persistiam condições de vida, perspectivas culturais e práticas institucionais que davam forma a algo como duas ordens diversas de escolaridade: uma dedicada à formação das minorias privilegiadas, e outra às maiorias subalternas da população. As possibilidades de acesso ao antigo ensino secundário eram limitadas e definiam na prática os dois padrões diversos de escolaridade. A antiga escola primária e as poucas escolas profissionalizantes existentes ministravam a então denominada educação popular. No outro polo, a educação das elites, definida a partir do ingresso no primeiro ciclo do ensino de tipo secundário, completava-se, depois, nos degraus superiores da escolaridade.

Esta situação apresentava sinais de mudança.

Nas décadas seguintes, a educação promovida pelos poderes públicos seria alterada, progressivamente, em duas direções: no sentido da inclusão dos adultos não alcançados pela escolaridade quando crianças, e na extensão das oportunidades de matrícula nos degraus ulteriores ao antigo ensino primário.

As iniciativas destinadas à expansão do atendimento escolar das crianças remontavam aos inícios do regime republicano. Na década de 1950, em ritmo e extensão muito desiguais conforme as regiões do país, o antigo ensino primário caminhava em direção ao atendimento de parcelas cada vez mais amplas da população infantil. Em parte das áreas urbanas das regiões mais desenvolvidas, o antigo ideal de extensão da escolaridade fundamental a todas as crianças já parecia ser realizável num futuro próximo. 
É importante reiterar que esta política de extensão do ensino elementar restringia-se à população infantil.

A inclusão de jovens e adultos iletrados nas políticas públicas de educação era ainda incipiente. 0 recenseamento geral de 1940 revelara que mais da metade da população acima de 15 anos de idade era constituída por analfabetos. Essa evidência do atraso educacional estimulava críticas e, ao mesmo tempo, reforçava as possibilidades de atuação de instituições e educadores comprometidos com a extensão da escolaridade básica a todos os habitantes - crianças, jovens e adultos. Até então, os cuidados com o atendimento às carências educacionais de jovens e adultos analfabetos ou pouco escolarizados eram objeto de iniciativas pontuais e fragmentárias. A bibliografia disponível registra alguns movimentos de pequena abrangência em poucos centros urbanos. 0 Exército nacional instituíra escolas regimentais de alfabetização de recrutas analfabetos; o Distrito Federal e unidades da federação mantinham classes noturnas de ensino de adultos.

Criado em 1938, o Instituto Nacional de Estudos Pedagógicos (INEP) merece destaque entre os agentes institucionais defensores da necessidade de uma política mais abrangente de educação para todos. Já nos últimos anos do Estado Novo, a União recomendava às unidades federadas que ampliassem o atendimento a jovens e adultos iletrados. Uma política oficial mais efetiva nessa direção somente seria inaugurada em 1947, com a criação de um Serviço de Educação de Adultos, no Departamento Nacional de Educação, e a concomitante instituição da Campanha Nacional de Educação de adolescentes e adultos analfabetos. Embora os recursos financeiros, humanos e administrativos fossem bastante limitados, fixava-se como objetivo mais amplo da Campanha o atendimento a todos os adultos ainda carentes de educação elementar.

Pelo menos no campo da declaração de intenções, a União consolidava o reconhecimento de compromisso de extensão do ensino fundamental a todos os habitantes. Organizada a partir da incorporação dos recursos humanos e administrativos já disponíveis nas redes escolares do ensino primário dos estados e territórios, a Campanha institucionalizou a alfabetização de adultos em todo o país. A colaboração das administrações das unidades federadas implicava a criação de serviços ou comissões locais de educação de jovens e adultos analfabetos. Essa inclusão da educação de jovens e adultos entre as obrigações permanentes das administrações estaduais favoreceu a continuidade da prática, mesmo após a extinção da Campanha Nacional de Educação (BEISIEGEL, 1974).

Outros empreendimentos da União contribuíram para estender a educação fundamental a adolescentes e adultos durante a década de 1950. Cabe mencionar, entre elas, a Campanha Nacional de Educação Rural, de 1956, e a Campanha Nacional de Erradicação do Analfabetismo, de 1958, especialmente importante nestas observações, porque já focalizava a educação de jovens e adultos iletrados sob valores e orientações do nacionalismo desenvolvimentista.

Não obstante a importância atribuída pela coordenação da Campanha de 1947 à sua ação social mais ampla, enquanto valorização da escola nas comunidades, com reflexos positivos na própria educação infantil e como instrumento de permeabilização das populações à atuação modernizadora do Estado, na prática os trabalhos foram 
progressivamente reduzidos ao seu aspecto mais simples e imediato de suplementação da alfabetização e de outros conhecimentos não obtidos na escola por jovens e adultos quando crianças. Esse caráter de "ensino supletivo" de conteúdos elementares da escola primária foi crescentemente questionado ao longo da década de 1950. A Campanha de Erradicação do Analfabetismo envolvia mudanças significativas nas orientações. Agora, a dimensão escolar surgia nos trabalhos como variável dependente do objetivo mais amplo de promoção do desenvolvimento nacional. Sob este aspecto, a Campanha de Erradicação prenunciava orientações progressivamente assumidas pela educação de jovens e adultos nos anos posteriores. Nesta nova perspectiva, os educadores e administradores do Departamento Nacional de Educação, e educadores, administradores e professores das redes oficiais do ensino primário das secretarias de educação das unidades federadas, mais diretamente envolvidos nos trabalhos iniciados em 1947, serão rapidamente substituídos por outros figurantes. Agora, entre os agentes da educação popular praticada no final da década de 1950 e na década subsequente, encontram-se organizações e participantes estranhos ao campo profissional da educação escolar. Envolvem-se nestes trabalhos especialmente os jovens da Juventude Universitária Católica (JUC), da Juventude Estudantil Católica (JEC), e da União Nacional de Estudantes (UNE). Cabe neste aspecto uma menção especial ao Instituto Superior de Estudos Brasileiros (ISEB), à hierarquia e ao laicato católico em geral, além de outros agrupamentos ideologicamente orientados. Constituía-se, nesse percurso, uma nova acepção da expressão educação popular.

\section{Educação escolar de crianças e ensino supletivo para adultos}

Até então, a literatura sobre a educação utilizava a expressão educação popular para designar especialmente as orientações e características dos conteúdos e práticas do ensino entendido por intelectuais, políticos, administradores e educadores em geral, como fundamentais à educação das classes populares. Na verdade, era uma educação escolar fundamental entendida como necessária para todos os habitantes. Mas, quando essa escolaridade fundamental a todos os cidadãos era examinada como a educação necessária às classes populares, a expressão demarcava os limites do que era entendido como necessário, possível e suficiente para a grande maioria da população. As dificuldades de acesso ao ginásio estabeleciam claramente os limites. Essa educação escolar popular envolvia sobretudo a atuação de professores primários nos grupos escolares e nas escolas unidocentes rurais, acessiveis às maiorias subalternas da população.

As primeiras iniciativas de promoção de políticas públicas de educação de jovens e adultos analfabetos não escaparam a essa imersão no extenso universo da burocracia escolar construída para o ensino infantil. Lourenço Filho, principal inspirador e realizador dessas iniciativas, já defendia, em artigo de 1945, a necessidade de atentar para as especificidades da educação básica do adulto iletrado (BEISIEGEL, 2006). Mas, nas condições disponíveis para a realização dos trabalhos, a educação dos analfabetos reduziu-se à simples repetição aos adultos, à noite, daquilo que os professores do ensino primário já ofereciam às 
crianças no período diurno. Essa acepção tradicional de educação popular caracterizavase pelo foco nas atividades dos professores e administradores das escolas primárias. Seus conteúdos consistiam basicamente na transmissão de conhecimentos elementares de leitura, escrita e cálculo, bem como de rudimentos de história, geografia, ciências e noções básicas de higiene e saúde. Não obstante a importância em geral atribuída por educadores e sociólogos às funções de controle social da educação escolar, os vínculos entre a ordem social e essa educação básica tradicional eram difusos e só indiretamente perceptíveis.

\section{Educação popular como formação da consciência}

É bem verdade que a inclusão de jovens e adultos das massas iletradas entre os destinatários da escolaridade básica, de alguma forma, por si mesma, já alterava a natureza dessa prática social. Na época, o analfabeto não tinha direito de voto. Ao alfabetizar-se, imediatamente incluía-se entre os participantes das disputas eleitorais.

Mas, nas práticas observadas a partir do final dos anos 50, muito além desta ampliação do eleitorado, o processo educativo buscava transformar o educando em agente ativo na realização de um determinado projeto de sociedade no futuro. Não bastava possibilitar ao adulto o direito ao voto. Mais do que isso, era necessário dotá-lo da consciência da importância desse voto como recurso de atuação. Esta nova acepção de educação popular poderia, assim, definir-se como um campo de luta entre correntes ideológicas politicamente atuantes na busca do exercício de influência sobre as grandes massas desfavorecidas da população. Naturalmente esta nova educação popular solicitava outros conteúdos e outros agentes educativos. 0 foco no aprendizado dos conteúdos tradicionais da escolaridade primária deslocava-se para a compreensão das possibilidades de atuação do educando na preservação ou na transformação da ordem social. As tensões da intensa luta política e ideológica desse período passam a integrar e a determinar as características e orientações da educação popular.

Encontram-se bons exemplos da gestação desse novo entendimento da educação popular. Em aula inaugural do curso regular do ISEB, no primeiro semestre de 1956, Álvaro Vieira Pinto examinou o que designava como uma "noção social de educação", como um processo voltado para a unificação e aceleração da consciência do povo em direção à realização de um “desenvolvimento nacional autêntico". Em análises sobre os efeitos das mudanças sociais que acompanhavam a constituição da sociedade urbana e industrial no país, observou que as reivindicações de salário, transportes, moradia, além de outras, seriam expressões fenomênicas da necessidade de desenvolvimento nacional. Percebidas pela população como dificuldades colocadas pelas novas condições de vida, deveriam ser captadas pelo filósofo, interpretadas como expressões da necessidade de mudanças, rearticuladas sob a forma de um projeto nacional de desenvolvimento, e, em seguida, devolvidas pela ação educativa às suas origens na população. Estaria exatamente aí a atribuição da educação social. 0 projeto de um desenvolvimento nacional autêntico determinaria os conteúdos da educação social então necessária. Propostas como esta e como outras produzidas pelos intelectuais reunidos no ISEB encontraram forte ressonância em diferentes setores da coletividade (BEISIEGEL, 1982). 
A comunicação apresentada pela equipe de Pernambuco, em 1958, ao Segundo Seminário Nacional de Alfabetização, já exemplificava a presença dessas propostas entre os educadores. 0 relator, Paulo Freire, fundamentando-se em ideias gerais que vinha consolidando durante a elaboração de uma tese acadêmica apresentada no ano seguinte à Escola de Belas Artes de Pernambuco, subordinava a discussão do analfabetismo entre adultos ao exame das condições de vida nos mocambos do Capibaribe e às correspondentes exigências de desenvolvimento nacional. Outro marco importante na formação destas novas perspectivas de compreensão da educação popular aparece em 1960, no convênio celebrado entre a União e a CNBB para a constituição e o funcionamento do Movimento de Educação de Base (MEB). Ainda em 1960, a criação do Movimento de Cultura Popular (MCP) do Recife, e da Campanha de Pé no Chão Também se Aprende a Ler, em Natal, consolidam e enriquecem as novas orientações da educação popular. Em 1962, o MCP está nas origens da criação do método Paulo Freire de Alfabetização de Adultos. Devese igualmente ao Movimento a elaboração do Livro de Leitura para Adultos, também conhecido na época como a Cartilha do MCP, largamente empregado no Serviço de Alfabetização Radiofônica (SAR) do Recife, e por trabalhos de alfabetização empreendidos pela UNE em outras regiões do país.

É importante assinalar a forte presença do então denominado pensamento progressista da igreja católica na elaboração conceitual desta nova acepção de educação popular. Enquanto seus adversários comunistas preocupavam-se, prioritariamente, com a formação mais restrita de militantes entre os operários urbanos, o pensamento e a prática dos católicos afınados com as necessidades da disputa ideológica, intensificada no após guerra, voltavase decididamente para os recursos de preservação e aprofundamento da influência sobre as grandes maiorias desfavorecidas da população, nas áreas urbanas e rurais. Encontramse, também, nos trabalhos de educação popular empreendidos na época, muitos indícios de repercussões da cartilha Venceremos e do livro do professor Alfabeticemos, elaborados para o Ano Nacional da Educação de Cuba, em 1961. Por seus respectivos conteúdos, A Cartilha do MCP, de 1962, o livro Viver é Lutar, do MEB, de 1963, e os materiais didáticos produzidos no âmbito da Cruzada $\mathrm{ABC}$ e do Mobral, nos anos posteriores à deposição do governo Goulart, não podem faltar nas análises sobre as orientações da educação popular nesta nova acepção do conceito (PAIVA, 1973). Em todos esses documentos encontram-se claramente explicitado o foco em concepções políticas e ideológicas comprometidas ou com a persistência ou com a transformação da ordem social.

Os primeiros trabalhos publicados por Paulo Freire oferecem um bom exemplo das mudanças observadas na conceituação da educação popular. No artigo Conscientização e Alfabetização - uma nova visão do processo (FREIRE, 1963), o educador relata que, em 1961, enquanto coordenador do projeto de educação de adultos do Movimento de Cultura Popular (MCP), promoveu o lançamento de duas instituições básicas de educação popular, o Círculo de Cultura e o Centro de Cultura. 0 Círculo de Cultura reunia pessoas do povo para debates com o objetivo de "aclaramento de situações problemáticas e de busca da ação suscitada pelo aclaramento das situações examinadas”. Os debates envolviam problemas levantados em diálogos do educador com os participantes. Em suas próprias palavras, 
Nacionalismo, remessa de lucros para o estrangeiro, evolução política do Brasil, desenvolvimento, analfabetismo, voto do analfabeto, socialismo, comunismo, "direitismo", SUDENE, democracia, Ligas Camponesas, eram, entre outros, temas que se repetiam de grupo a grupo. (FREIRE, 1963, p. 11).

As questões envolvidas nas discussões sobre esses temas eram "tanto quanto possível reduzidas a ajudas visuais e apresentadas em forma dialogal aos grupos. Os resultados eram surpreendentes. Com seis meses de experiências, perguntávamos a nós se não seria possível encontrar um método ativo que nos desse resultados iguais, na alfabetização, aos que vínhamos obtendo na análise de aspectos da realidade brasileira" (BEISIEGEL, 1982).

As origens do método, logo após proposto pelo educador para a conscientização e a alfabetização do adulto, estavam aí, claramente, assentadas nas práticas anteriores da educação popular politizadora de setores "proletários ou semiproletários" do Recife, independentemente de seus níveis de escolaridade. Já em suas origens, o método Paulo Freire de alfabetização de adultos explicitava inequivocamente suas raízes e orientações na busca de práticas conscientizadoras.

Impõe-se aqui observar que as duas modalidades típicas de educação popular, a educação popular tradicional, regular ou supletiva, e a educação popular "conscientizadora", ora constituídas no plano discursivo, não implicam substituição radical de antigas práticas por outras de natureza diversa. Em quase todas as práticas da educação popular observadas nesse período, os trabalhos da alfabetização aparecem entre os objetivos principais das atividades. A necessidade da alfabetização (leitura, escrita e cálculo) a duras penas havia penetrado o imaginário da coletividade e apresentava-se como forte argumento de justificação para empreendimentos no campo educacional.

A esse respeito é necessário lembrar que, ao longo da história do país, desde os primeiros movimentos de independência, as afirmações da necessidade de educação fundamental da população integraram programas formulados pelas elites intelectuais dominantes. Já nos movimentos da independência e logo depois, nas discussões da constituinte de 1823, e mesmo na Constituição Outorgada, em 1824, encontram-se referências à instrução primária e aos níveis ulteriores da escolaridade. Nas condições da vida social no país, as propostas legais sobre a educação eram figuras de ficção. Eram temas de discussões nos círculos de políticos e intelectuais, mas não encontravam qualquer respaldo no comportamento ou nas aspirações da população. Mesmo após a implantação do regime republicano, a incorporação das reivindicações de educação básica pelas classes populares foi demorada. Variável nas diferentes regiões, dependia do lento avanço do processo mais amplo de urbanização e modernização da vida social. Encontram-se na legislação e na historiografia educacional muitas referências aos esforços públicos de imposição do exercício dos direitos e deveres educacionais, progressivamente inseridos na legislação.

Mas este sentimento de necessidade de educação escolar básica acabou penetrando o ideário coletivo. Já na segunda metade do século passado, os movimentos educacionais voltados para as populações desfavorecidas encontravam na proposta de aprendizado da 
leitura e da escrita um importante apelo à participação. Embora segmentos da população, sobretudo nas idades mais avançadas, ainda resistissem, a necessidade de estender a escolaridade fundamental a todas as crianças, e, também, aos adolescentes e adultos ainda analfabetos, vinha sendo progressivamente incorporada pela coletividade. Por isso mesmo, os movimentos de educação de jovens e adultos analfabetos encontram nesta busca da alfabetização uma justificação categórica, mesmo quando os objetivos centrais da proposta eram mais amplos e envolviam prioritariamente a formação da consciência da necessidade de transformação da ordem social.

0 recrutamento de jovens e adultos e, mais ainda, sua frequência nos trabalhos escolares, aparecem como dificuldade comum nos relatos de campanhas de alfabetização e outros movimentos de educação popular empreendidos na segunda metade do século passado. Associada à necessidade de domínio da comunicação indireta imposta pela urbanização, a crescente valorização social do conhecimento da leitura e da escrita era um estímulo ao adulto, um recurso significativo no enfrentamento das dificuldades de frequência às aulas e de persistência nas atividades escolares.

\section{Expansão das oportunidades de acesso à escolaridade}

Ainda nos meados do século anterior, acompanhando com atraso variável nas diferentes regiões um processo já iniciado nos países mais avançados no campo educacional, o Brasil assistiu ao início da ruptura dos limites que separavam a educação das elites e a educação das massas populares. 0 ensino secundário passou a absorver parcelas mais amplas de crianças das classes médias e populares muito antes da realização efetiva da universalização da escola primária. A progressiva criação de ginásios noturnos, a reforma do ensino iniciada no Estado de São Paulo, em 1967, e a lei federal de Reforma do Ensino de Primeiro e Segundo Graus, de 1971, consolidaram no plano legal a exigência de uma escolaridade básica de oito anos para a população em idade escolar. Na última década do século passado, a lei de diretrizes e bases incluiu na escolaridade básica todos os degraus anteriores ao ensino superior, da escola infantil até a escola de nível médio. Certamente, a realização prática dos ideais incorporados na legislação continuava distante no plano das realidades sociais. Mas a educação escolar avançou bastante na extensão das oportunidades educacionais.

0 crescente número de alunos diplomados no ensino de nível médio ampliou a pressão por ingresso no ensino superior. Expressões da insatisfação provocada pela procura não absorvida nas instituições existentes aparecem já nos anos 60, nos movimentos dos denominados excedentes dos exames vestibulares. Constituída por jovens e adultos em parte já inseridos no mercado de trabalho, com possibilidades de pagar mensalidades, essa nova clientela foi parcialmente absorvida por estabelecimentos mantidos pela iniciativa privada. A notável expansão da rede de ensino superior particular, e, em escala bem menor, a criação de novas escolas superiores públicas federais, estaduais e mesmo municipais, alargaram bastante a oferta de matrícula. Nas últimas décadas, segmentos consideráveis dessa procura foram atendidos indiretamente pelo poder público, por diversos procedimentos de financiamento de vagas em escolas particulares. Os números da expansão da matrícula no ensino superior são impressionantes: um total de 52.585 
alunos de todos os cursos no Brasil, em 1950 (CUNHA, 1982, p. 104), evoluiu para mais de sete milhões de matrículas, em 2013 (BRASIL, 2014).

Desde as últimas décadas do século anterior, no ensino de primeiro e segundo graus, com raras exceções, a escola pública vinha sendo visualizada pela população como a "escola dos pobres". Quem podia pagar optava pela escolaridade dos filhos nas escolas particulares. Os procedimentos adotados pela administração contribuíram fortemente para essa desqualificação do ensino público. Os expedientes usualmente mobilizados com vistas à ampliação das vagas somavam-se às sempre reiteradas consequências da miséria popular, nas explicações das dificuldades de rendimento da escolaridade. Há muito tempo, a escassez de recursos vinha consagrando a adoção das denominadas soluções de emergência no atendimento da população no ensino público. Como exemplos, nas áreas rurais do país, o atendimento escolar dependia das antigas escolas unidocentes (comuns e de emergência), na grande maioria entregues aos cuidados de leigos muito mal remunerados pelas prefeituras municipais. Nas regiões metropolitanas do Estado de São Paulo, a expansão da oferta de vagas no ensino primário foi viabilizada pela multiplicação de períodos de funcionamento dos prédios disponíveis, com a consequente diminuição do tempo de permanência do aluno nas classes. Nos primeiros anos da década de 1960, era comum o uso das instalações em três, quatro ou mais períodos diários de funcionamento. De igual modo, quando a procura de vagas no ensino secundário excedeu às possibilidades de atendimento nas escolas públicas então existentes, adotou-se a prática da criação de seções desses ginásios oficiais mais antigos, em período noturno, nos prédios ocupados durante o dia pelas escolas primárias.

A ampliação das possibilidades de atendimento à procura do ensino superior de alguma forma seguiu a mesma lógica dos procedimentos adotados para os degraus anteriores da escolaridade, no geral determinados pela escassez relativa de recursos, que induzia a busca da produção de mais serviços com os menores investimentos. Mas, neste caso, os investimentos necessários à acolhida dos novos pretendentes ao ingresso na escola superior foram delegados à iniciativa particular. Um importante trabalho divulgado pelo NUPES, em 2003, registra que o ensino superior cresceu "de maneira extraordinária entre 1965 e o final da década de 70” (DURHAM, 2003, p. 17). A iniciativa privada foi capaz de absorver a maior parte dessa demanda por vagas,

\footnotetext{
[...] porque se concentrou na oferta de cursos de baixo custo e no estabelecimento de exigências acadêmicas menores tanto para o ingresso como para o prosseguimento dos estudos até a graduação. [...] Apesar de haver a criação de novas universidades particulares que já eram vinte, em 1975, a expansão de fato se deu, em grande parte, através da proliferação de escolas isoladas, concentradas na oferta de cursos de baixo custo e menores exigências acadêmicas: administração, economia e formação de professores. (DURHAM, 2003, p. 18).
}

No âmbito desta ampla abertura de oportunidades de acesso ao ensino superior definia-se uma nova modalidade de expressão das desigualdades. Encontram-se frequentemente nos meios de comunicação referências a um novo aspecto de expressão das desigualdades sociais no ensino: a população pobre, atendida no ensino básico pela 
escola pública, só teria acesso ao ensino superior pago em estabelecimentos privados de qualidade inferior. As universidades públicas (e mesmo as universidades e escolas particulares de melhor qualidade) estariam reservadas aos jovens formados nas escolas secundárias e colégios particulares somente acessíveis às elites privilegiadas.

A transformação nas instituições escolares foi real e profunda. A expansão do atendimento escolar no antigo secundário, depois no ensino médio, e, atualmente, no superior, embaralharam concepções, ideias, crenças e sentimentos antes consolidados a propósito da educação escolar. Mas as questões e os desafios colocados pela educação popular permanecem. A desigualdade na educação é real, embora suas manifestações já não sejam tão claras como nos meados do século anterior. Ainda faz sentido falar em profundas diferenças entre a educação escolar dos pobres e a educação acessível aos segmentos privilegiados. As desigualdades na educação escolar, expressões quase inevitáveis das desigualdades sociais, somente mudaram as formas de sua manifestação.

\section{O ensino superior em Paulo Freire}

Paulo Freire diplomou-se em Direito, em 1947. Após uma primeira experiência na advocacia, desistiu da ocupação e assumiu o setor de educação do recém-criado SESI de Pernambuco, onde permaneceu até 1957 . Dedicou-se desde muito cedo a atividades no magistério, inicialmente no ensino secundário, e, depois, no ensino superior. Lecionou História e Filosofia da Educação, na Escola de Serviço Social e na Escola de Belas Artes de Pernambuco. Atuou regularmente no ensino universitário também no exterior: no Chile, nos Estados Unidos, na Suíça, e no Brasil, após 1980. Algumas apostilas de aulas ministradas nos primeiros tempos, em Pernambuco, dão indícios dos conteúdos e orientações de sua atividade no magistério. Percebe-se nesses documentos que suas aulas correspondiam coerentemente ao que defendia nos primeiros escritos em 58, 59 e 63. As aulas, assim como as atividades que assumiu no Movimento de Cultura Popular do Recife, constituíam-se em laboratório da intensa procura de articulação da formação teórica e da atuação no campo educacional. Progressivamente alargados e enriquecidos no estudo de novos autores e na reflexão sobre as experiências vividas no Brasil e no exterior, os conteúdos e orientações de sua atividade no ensino superior podem ser acompanhados na leitura de suas publicações posteriores.

Marcado pela forte presença de autores católicos de vanguarda, e do nacionalismo desenvolvimentista formalizado no Instituto Superior de Estudos Brasileiros (ISEB), seu primeiro livro, Educação e atualidade brasileira (FREIRE, 1959), apresentado como tese de concurso à Escola de Belas Artes de Pernambuco, continha críticas às orientações e às práticas tradicionais da educação escolar de uma sociedade oligárquica envelhecida, incompativel com as exigências de um Brasil já prenunciado na rápida transição para uma nova sociedade. As formulações sobre o homem, o processo educativo, e a atualidade brasileira, eram abrangentes e, a partir delas, o educador examinava criticamente os diferentes níveis e ramos da educação escolar. Mas as observações sobre o ensino superior eram escassas e pouco aprofundadas. No capítulo mais diretamente dedicado à caracterização e à crítica dos diferentes degraus da escolaridade, a atenção e o espaço 
dados ao ensino superior ocupam pouco mais de duas páginas (FREIRE, 1959, p. 115117). No que respeita ao ensino superior, as publicações posteriores pouco acrescentam às observações da tese de 59. 0 artigo Escola primária para o Brasil, de 1961, acompanha e aprofunda, em alguns aspectos, ideias e observações já assentadas naquele trabalho. 0 texto Conscientização e alfabetização - uma nova visão do processo, de 1963, divulgava ideias e procedimentos envolvidos no método de alfabetização de adultos. Escritos posteriores, publicados após a mudança para o Chile, acentuavam a imagem de um educador dedicado ao trabalho educativo junto aos desfavorecidos. Os livros Educação como Prática da Liberdade, Extensão ou Comunicação, e outros escritos desse período, incluem-se igualmente nessa caracterização.

As orientações de Paulo Freire em seus trabalhos no ensino superior, nestes primeiros tempos, estão claramente expostas em suas atividades na Escola de Serviço Social, na Escola de Belas Artes da Universidade do Recife (FREIRE, 1959), e nos trabalhos que realizou no Movimento de Cultura Popular (MCP) e no Serviço de Extensão Cultural (SEC) da Universidade. Conforme relatos do educador, elas procedem de experiências mais antigas, especialmente no contato com trabalhadores no SESI de Pernambuco. No MCP, essas mesmas orientações aparecem na criação do Centro de Cultura e do Círculo de Cultura, e, logo depois, nas propostas do método de conscientização e alfabetização de adultos. Concebido e ensaiado pela primeira vez no Centro de Cultura Dona Olegarinha, do MCP, o método de alfabetização continuou como foco das atividades do grupo de trabalho organizado por ele no Serviço de Extensão Cultural (SEC) da Universidade do Recife. Freire relata conversas com o Reitor e assessores da reitoria, desde os anos finais da década de 50, sobre a necessidade da criação de um serviço de extensão cultural na universidade. Quando, afinal, o serviço foi instituído, em 1963, o educador foi designado como seu primeiro diretor. Interessa registrar aqui observações de Paulo Freire sobre os diálogos que mantinha com os participantes do Círculo de Cultura do MCP. Quando a conversa incidia sobre questões de disciplinas que ele não dominava, procurava auxílio entre os colegas da universidade, professores de Economia, Sociologia, Antropologia e outras disciplinas (BEISIEGEL, 1982, pp. 208-212) Em conjunto, os estudos nos campos da Educação e das Ciências Humanas, empreendidos na atividade didática no ensino superior; a participação na criação e na direção MCP; as instituições culturais que criou no Movimento; e a criação do método de alfabetização, harmonizam-se, coerentemente, nos momentos iniciais do longo caminho do educador. Procurando apoio desde esses primeiros tempos num amplo elenco de educadores e outros intelectuais no campo das humanidades, Paulo Freire dedicou-se intensivamente à procura de respostas criadoras para questões colocadas pelas condições de vida das massas desfavorecidas.

Pedagogia do oprimido, concluída no Chile em 1968, dialogava com grupos de intelectuais bem diversos daqueles que estavam presentes em seus primeiros trabalhos. Alargava e aprofundava as análises sobre a inserção da educação na dinâmica de uma sociedade opressora. A interação antagônica de opressores e oprimidos encontrava expressão nas características dos tipos ideais de educação bancária e problematizadora, bem como nos traços distintivos do diálogo entre educadores e educandos correspondentes a cada um desses tipos. 
Não obstante o nível de abstração e abrangência das formulações, é razoável entender que o educador refletia sobre experiências passadas e possibilidades de futuro ainda sob a perspectiva do processo educativo junto às populações subalternas. É também possivel reiterar que, mesmo quando examinava questões específicas do ensino superior, seus trabalhos continuavam focalizados no processo de emancipação dos oprimidos. Mas é indispensável observar que a exposição aprofundada da situação dos oprimidos envolvia, também, implícita ou explicitamente, ambos os polos da opressão. As orientações de uma educação comprometida com a emancipação do oprimido eram a outra face de uma educação voltada para a perpetuação da opressão. E esclarecia também que as ações orientadas para a eliminação da opressão somente poderiam decorrer da atuação dos oprimidos. A partir das análises que constituem os tipos antagônicos da educação bancária e da educação problematizadora era possível deduzir quais seriam as posições do autor a propósito das instituições do ensino superior. Outros trabalhos posteriores caminham nessa mesma direção. Os estudos sobre o papel educativo das igrejas na América Latina (FREIRE, 1976), notadamente nas análises a propósito da atuação dos sacerdotes identificados com a emancipação dos oprimidos, em certa medida podem ser alargados para abarcar as instituições educativas e os educadores em geral. Mas é necessário reafirmar que, realizada por outros que não o próprio educador, esta operação intelectual poderia variar consideravelmente a partir das perspectivas dos diferentes observadores. As Cartas à Guiné Bissau (FREIRE, 1977), endereçadas aos responsáveis pela educação popular na antiga colônia, alcançam explicitamente outros degraus da escolaridade: dedicados à formação das elites locais, vistos como provedores dos quadros da administração colonial, os liceus são avaliados a partir dos novos interesses da educação de cidadãos, agora responsáveis pela construção de um país independente. 0 livro merece atenção, neste artigo, como mais um exemplo dos procedimentos analíticos de Paulo Freire.

Estes procedimentos podem ser confirmados, já no Brasil, no seminário sobre Universidade e compromisso popular, promovido em 1986 pela PUC-Campinas. Na exposição intitulada $O$ compromisso popular da universidade, Freire analisa agora explicitamente questões específicas do ensino superior. Começa por apontar o caráter eminentemente político do tema. Ao longo da exposição, qualifica o que entendia como o processo de identificação de uma universidade com os interesses do povo. Inclui, entre os indicadores dessa orientação, o apoio da universidade à melhoria da escola pública de ensino básico, o respeito e assistência à formação permanente de seus professores, bem como a criação de melhores condições de trabalho docente:

[...] a eficiência da escola pública passa pelo respeito que o poder público deve aos professores e professoras, passa por melhores salários, passa pela formação permanente dos professores e, também, pela sua opção política e pela coerência entre o que fazem e o que verbalizam. Passa pela reorientação do tempo curricular para que as crianças disponham cada vez mais de maior tempo útil dedicado a conhecer. (FREIRE, 1986, p. 17).

Afırma, enfaticamente, que a aproximação da universidade aos interesses das classes populares não poderia ser entendida como ausência de compromisso com o rigor 
e a competência. Pelo contrário, envolvia rigorosa preocupação com a qualidade da docência e da pesquisa científıca. Freire menciona a ambiguidade radical da universidade privada mas de espírito público, exemplificado-a na oposição entre greves de servidores que reivindicam melhores salários e greves de estudantes que reivindicam custos menos elevados para sua educação. Este tema, afirma, não poderia escapar do horizonte de quem sonha com uma universidade comprometida com o povo. As dificuldades geradas no âmbito dessa ambiguidade seriam ampliadas à medida que o desenvolvimento das forças produtivas necessariamente provocaria reações populares no sentido da

[...] demanda de educação para os filhos do povo, por parte dos pais e mães destes filhos, e na demanda de educação para elas e para eles também. Indo além da consciência de si - passo que não se dá mecanicamente, a classe trabalhadora exigirá cada vez mais. (FREIRE, 1986, p. 10).

Os procedimentos analíticos do educador explicitam-se nessas considerações. Como testemunhos exemplificadores, retoma situações vividas após a publicação da Pedagogia do oprimido, quando foi procurado por sindicalistas italianos para conversar, entre outras questões, sobre os horários de estudo que haviam conseguido introduzir na jornada de trabalho, e as tentativas de setores patronais que, forçados a atender a essa reivindicação, pretendiam determinar os conteúdos do currículo e a escolha dos professores. As observações de Freire a esse respeito decorrem diretamente de suas análises sobre a interação entre opressores e oprimidos:

Se os operários tivessem cedido teriam, ganho uma batalha, mas perdido a guerra. Escolhendo os conteúdos, a maneira como tratá-los por meio da seleção dos professores, os grupos patronais poriam em prática a compreensão de classe que têm da formação do trabalhador, quer dizer, tentariam a sua reprodução como tal, como classe submetida. (FREIRE, 1986, p. 12).

Nessa mesma linha de reflexões, Freire menciona conversa recente com representantes de uma liderança sindical para discussão sobre "a criação de um centro ou instituto, em São Paulo, para a formação permanente de seus quadros”. Haveria já agora

[...] fração grande da classe trabalhadora procurando assumir a responsabilidade de sua formação porque começa a perceber, mais do que simplesmente sentir, que a classe dominante não pode formar a dominada, a não ser para que esta se reproduza como tal. (FREIRE, 1986, p. 11).

É interessante observar que no livro de 1968 essas reflexões são trabalhadas abstratamente, no âmbito da interação entre opressores e oprimidos. No final do século, nestas observações de 1986, e no livro Pedagogia da esperança, de 1992, as mesmas situações são trabalhadas sob a perspectiva da oposição entre classes sociais e construção da consciência de classe: "A formação da classe dominada com vistas à transformação da sociedade injusta é tarefa da classe dominada mesma e de quem a ela realmente adira" (FREIRE, 1986, p. 11). Encontram-se no artigo outras exemplificações de temas trabalhados mais abstratamente em Pedagogia do oprimido. A iniciativa das lideranças sindicais que 
procuravam criar, em São Paulo, um instituto de formação de trabalhadores, é vista por Freire como uma possível semente do que poderá vir a ser uma universidade popular.

Esta liderança percebeu na sua prática sindical, também política, que o desenvolvimento e a eficácia de sua luta, a partir de um certo momento, começava a exigir dela uma compreensão mais cientificamente rigorosa da própria luta e do contexto social, histórico e econômico em que ela se dá. É que a prática, embora fundamental e indispensável, não é, contudo, sua própria teoria. (FREIRE, 1986, p. 23).

Essas análises exprimem bem as expectativas de um educador radical nas últimas décadas do século passado. E mesmo quando tomam como referência desafios colocados pelo trabalho numa universidade privada, as observações apontam para questionamentos abrangentes, compatíveis com suas análises nas obras anteriores.

São particularmente interessantes os temas relacionados à procura do ensino superior pelas classes populares. Embora os efeitos da expansão da produção capitalista apareçam em suas observações sobre a expansão da procura de escolaridade, as análises focalizam especialmente a atuação de trabalhadores politizados, empenhados na formação em nível superior como instrumento da luta em favor da emancipação popular. Na Pedagogia da esperança (FREIRE, 1992), inclui entre as consequências significativas da publicação de Pedagogia do oprimido, as visitas que recebeu de lideranças sindicais europeias interessadas em dialogar com ele a propósito da condução da política operária. Ainda em Pedagogia da esperança, em resposta a críticas de intelectuais marxistas, sobre a utilização dos conceitos de opressores e oprimidos nas análises sobre as desigualdades geradas pelo modo capitalista de produção, Freire observa que já empregara a teoria das classes sociais em numerosas oportunidades, o que por outro lado não o impedia de estudar as contradições sob uma perspectiva mais geral e abstrata. A comunicação apresentada no seminário da PUC-Campinas demonstra que o educador, agora, analisava a aspiração de trabalhadores à educação superior sob a perspectiva das questões levantadas pelas lideranças sindicais que o procuravam. A presença de trabalhadores era focalizada a partir dos interesses da classe trabalhadora. As questões colocadas pela incipiente presença de jovens das populações pobres nas escolas de nível superior ainda não encontravam respostas específicas nas reflexões do educador.

Convém observar que as expectativas das populações desfavorecidas não foram suficientemente trabalhadas na pesquisa educacional sobre os degraus superiores da escolaridade. Mas as informações disponíveis comportam reflexões preliminares provisórias, aceitáveis ao menos como referência para formulação de hipóteses de estudos posteriores.

A crise ora enfrentada pelo país, em seus desdobramentos econômicos, sociais, políticos e administrativos, terão consequências nos processos ora examinados. Não obstante, até aqui, o acesso de segmentos das classes populares ao ensino superior tem sido favorecido, entre outros fatores, principalmente pela identificação das escolas como campo favorável ao investimento privado nacional e estrangeiro na educação, nesse nível da escolaridade; pelo apoio encontrado por esses empreendimentos em políticas públicas de financiamento, sobretudo sob a forma de bolsas e empréstimos oficiais aos estudantes; 
e, principalmente, pelo efeito de demonstração gerado pela crescente presença de jovens das classes populares nas escolas superiores. Cabe observar, a esse respeito, que, por enquanto, a contribuição das ações afirmativas instituídas no ensino superior público, embora positiva e necessária, ainda é pouco efetiva na incorporação de candidatos dos segmentos menos favorecidos da população: a concorrência pelas vagas disponíveis atende ao acesso dos segmentos escolarmente mais competitivos nas categorias abrangidas nos seus critérios.

A percepção de possibilidades de obtenção de um diploma de ensino superior, e a consciência das dificuldades colocadas pelas condições de vida, convivem, contraditoriamente, nas aspirações de segmentos crescentes da juventude das classes populares das áreas urbanas. 0 ingresso nos cursos é difícil. A competição nos exames de acesso é intensa e seleciona jovens escolarmente mais preparados. Especialmente nas grandes metrópoles, a frequência às aulas, no período noturno, impõe sacrifícios. As mensalidades pesam bastante no orçamento, mesmo em escolas menos dispendiosas, instaladas com vistas ao atendimento de um alunado de poucos recursos econômicos. A escolha do curso também envolve dificuldades. Em muitos casos, as duras condições impostas pela realidade só viabilizam um leque de alternativas não compatíveis com as aspirações do estudante. 0 penoso enfrentamento dessas e de outras dificuldades encontra apoio na percepção, socialmente generalizada, da escolaridade como fator de melhoria nas condições de vida. A busca da ascensão social, nestas condições, realiza um tema clássico nos estudos sociológicos sobre as progressivas transformações observadas na sociedade capitalista, quando a ação coletiva voltada para a emancipação da classe dominada é progressivamente substituída pela busca individual de melhoria das condições de vida.

Freire faleceu em 1997. A procura de vagas e o progressivo acesso de jovens das classes subalternas no ensino superior ainda não apareciam, como problema grave, entre as preocupações da crítica conservadora. A graduação à distância, seus inegáveis recursos educacionais, sobretudo num país de dimensões continentais, como o Brasil, e também os riscos embutidos em seu aproveitamento comercial, ainda engatinhavam.

A luta individual de jovens ou adultos das classes subalternas por melhoria das condições de vida pelos caminhos da educação superior, mesmo que ainda não estivesse identificada explicitamente em análises específıcas de Paulo Freire, não era ignorada no conjunto de seus trabalhos. Sem dúvida alguma, é parte significativa de um daqueles temas essenciais embutidos ao longo de sua praxis de educador. Uma pesquisa dedicada ao "desvelamento" deste tema nas diferentes etapas de sua atividade, ao mesmo tempo apontaria apoio aos esforços pelo acesso à educação escolar superior, e crítica radical ao processo de captação dos menos favorecidos pelo mercado. 0 apoio é evidente, como aspecto indissociável de seus trabalhos: nos primeiros tempos, na criação dos Círculos de Cultura; na criação do método de conscientização e alfabetização; na participação nas especulações de intelectuais do MCP do Recife sobre as características e possibilidades de criação de uma universidade popular. Nesta identificação com as necessidades educacionais, prevalecem os temas que apontam para a valorização das condições da vida das coletividades oprimidas, o que por sua vez não exclui o apoio à luta por educação dos sujeitos individuais dessas coletividades. É bem verdade que esta questão deve ser examinada no âmbito de reflexões que apontam para uma ética dos interesses coletivos contra a avidez do individualismo. 
0 apoio à extensão da escolaridade às crianças, jovens e adultos do povo é acompanhado, desde o início de seus trabalhos, pela crítica às orientações da educação estendida às classes populares: no SESI de Pernambuco, quando resiste às práticas assistencialistas e autoritárias da instituição; na tese de 1959, na persistente objeção às práticas autoritárias da escola, em todos os ramos e níveis da atividade. A crítica é ainda mais notável no método de alfabetização de adultos, que rejeita até designações há muito tempo consolidadas no ensino: escola, classe, professor, aluno, aulas, currículo etc. A crítica focaliza sobretudo as orientações e os conteúdos autoritários e desumanizadores da escolaridade tradicional. Mais tarde, já no exterior, o contato com muitos outros intelectuais, igualmente exilados, e a convivência com outras correntes de pensamento, alargaram os alcance e o significado de suas críticas à educação escolar. Não seria exagero interpretar a ausência de manifestações de Paulo Freire sobre o ensino superior ora progressivamente acessivel às camadas mais pobres da população, como expressão de coerência com as posições críticas anteriores. Mas esta posição não pode ser entendida como atitude negativa à conquista de oportunidade de educação superior por jovens das classes populares. 0 ensino superior organizado para capturar o consumidor mais pobre seguramente não atenderia às características da educação emancipadora que preconizava. Mas, Paulo Freire sempre defendeu a importância da presença popular na escola, sobretudo na escola pública, mesmo quando as escolas existentes não atendiam às necessidades das populações oprimidas.

Em 1989, ao assumir a Secretaria Municipal da Educação de São Paulo, Freire de certo modo reencontrava suas origens de educador popular no SESI, no MCP do Recife, e na educação de jovens e adultos analfabetos. Nesta bagagem incluíam-se as sempre gratificadoras lembranças da convivência com educandos trabalhadores, e, também, da crítica que fazia às orientações e procedimentos da escola tradicional. Cabem aqui outras observações a propósito de possíveis contribuições de Freire ás práticas do ensino superior. Enquanto Secretário, dedicou-se intensamente à interação com o magistério das escolas municipais. No diálogo com os professores, insistia na importância do respeito às características socioculturais do alunado e na necessidade da implementação do diálogo, envolvendo todos os participantes, alunos, professores, servidores em todos os níveis, como fundamento do trabalho educativo. Talvez encontre-se aqui uma das muitas possibilidades de contribuição de Freire para a prática do ensino superior. É bem possível, mesmo hoje, que a consideração dos educadores pela bagagem sociocultural do aluno ingressante favoreça alcançar o melhor ponto de chegada ao final do processo.

Embora a conquista da possibilidade de acesso ao ensino superior por indivíduos das classes subalternas seja ainda incipiente, já é razoável envolver nesse nível da escolaridade algumas questões focalizadas pela educação popular. Entre elas, questões já colocadas nos meados do século passado pela inclusão de crianças e adolescentes das populações subalternas no antigo ensino secundário (BEISIEGEL, 1975). Críticas em quase tudo semelhantes são retomadas nestas últimas décadas, agora a propósito da educação superior. A má qualidade do ensino ministrado em escolas precárias, por professores pouco selecionados, a jovens despreparados para a escolaridade de nível superior, centraliza as críticas às mudanças. A valorização de uma excelente qualidade que teria marcado os 
estudos superiores no passado alimenta a rejeição a um processo apenas esboçado, mas já dificilmente reprimível, de expansão do atendimento popular em escolas superiores. Talvez a natureza e as implicações desta rejeição constituam a primeira das questões relevantes colocadas pelas mudanças ora observadas no ensino superior. Por isso mesmo é imperioso não colocar no mesmo prato da balança todas as críticas às escolas acessíveis às populações subalternas. São muito diferentes: algumas apontam para sua eliminação. Outras, reconhecendo sua importância, defendem providências para a melhoria de sua qualidade. Não obstante suas críticas às orientações e às práticas do ensino oficial, coerente com tudo o que propôs enquanto educador, Paulo Freire defenderia maior envolvimento do ensino público de nível superior na acolhida das reivindicações educacionais dos jovens trabalhadores. As observações disponíveis na comunicação ao seminário da PUCCampinas apontam claramente nesse sentido.

\section{Referências}

BEISIEGEL, Celso de Rui. A qualidade do ensino na escola pública. Brasília, DF: Liber Livro, 2006.

BEISIEGEL, Celso de Rui. A reforma e a qualidade do ensino. In: NAGLE, Jorge (Org.). Educação brasileira: questões de atualidade. São Paulo: Edart, 1975. p. 29-38.

BEISIEGEL, Celso de Rui. Estado e educação popular: um estudo sobre a educação de adultos. São Paulo: Pioneira, 1974.

BEISIEGEL, Celso de Rui. Lourenço Filho e a educação popular no Brasil. In PILETTI, Nelson (Org.). Educação brasileira: a atualidade de Lourenço Filho. São Paulo: Feusp, 1999. p. 103-126.

BEISIEGEL, Celso de Rui. Política e educação popular. São Paulo: Ática, 1982.

BRANDÃO, Carlos Rodrigues. Da educação fundamental ao fundamental na educação. Proposta, Rio de Janeiro, Suplemento 1, 1977.

BRASIL. Ministério da Educação. Instituto Nacional de Estudos e Pesquisas Educacionais Anísio Teixeira. Censo da educação superior 2013. Brasília, DF: MEC/INEP, 2014.

CUNHA, Luiz Antonio. A universidade crítica: 0 ensino superior na república populista. Rio de Janeiro: Civilização Brasileira, 1982.

DURHAM, Eunice Ribeiro. 0 ensino superior no Brasil: público e privado. São Paulo: Nupes, 2003.

FÁVERO, Osmar. Uma pedagogia da participação popular: análise da prática educativa do MEB - Movimento de Educação de Base (1961-1966). Campinas: Autores Associados, 2006.

FREIRE, Paulo. Ação cultural para a liberdade e outros escritos. Rio de Janeiro: Paz e Terra, 1976. 
FREIRE, Paulo. Cartas à Guiné-Bissau: registros de uma experiência em processo. Rio de Janeiro: Paz e Terra, 1977.

FREIRE, Paulo. Conscientização e alfabetização: uma nova visão do processo. Estudos Universitários, Recife, n. 4, p. 5-23, 1963.

FREIRE, Paulo. Educação como prática da liberdade. Rio de Janeiro: Paz e Terra, 1967.

FREIRE, Paulo. Educação e atualidade brasileira. 1959. Tese (Concurso para a Cadeira de História e Educação) - Escola de Belas Artes de Pernambuco da Universidade Federal do Recife. Recife, 1959.

FREIRE, Paulo. 0 compromisso popular da universidade. In: UNIVERSIDADE e compromisso popular. Campinas: Puccamp, 1986.

FREIRE, Paulo. Pedagogia da esperança: um reencontro com a pedagogia do oprimido. Rio de Janeiro: Paz e Terra, 1992.

PAIVA, Vanilda Pereira. Educação popular e educação de adultos. São Paulo: Loyola, 1973.

Recebido em: 05.02.2018

Aprovado em: 08.03.2018 